\title{
Correction to: \\ The Changing Role of Ancillary Health Care Service Providers: \\ An Evaluation of Health Diagnostic Laboratory, Inc. by Thompson S, Varvel S, Voros S, Thiselton D, Grami S, Turner R and Barron J. Population Health Management 2014;17(2):121-126. DOI: 10.1089/pop.2013-0030
}

N THE APRIL 2013 issue of Population Health Management (vol. 17, no. 2; 121-126) there was an error in the disclosure section. The following sentence is not correct: "The authors received no financial support for the research, authorship, and/or publication of this article."

This text had been corrected to read "Dr. Thompson received funding for research support from Health Diagnostic Laboratory, Inc."

Dr. Thompson apologizes for this omission.

The online version of this article has been corrected to reflect this. 